\title{
Correction to: Elucidating the processes and pathways enriched in buffalo sperm proteome in regulating semen quality
}

Bala Krishnan Binsila ${ }^{1}$ · Santhanahalli Siddalingappa Archana ${ }^{1}$. Laxman Ramya ${ }^{1}$. Divakar Swathi ${ }^{1}$. Sellappan Selvaraju ${ }^{1} \cdot$ NK . Shivakumar Gowda ${ }^{2} \cdot$ Din Taran Pal $^{2} \cdot$ Abu Rafay $^{3} \cdot$ Raghavendra Bhatta $^{4}$

Published online: 25 January 2021

(c) Springer-Verlag GmbH Germany, part of Springer Nature 2021

\section{Correction to: Cell and Tissue Research https://doi.org/10.1007/s00441-020-03303-9}

The published online version contains an incorrect Fig. 5 image. The correct figure is given below.

The original article can be found online at https://doi.org/10.1007/ s00441-020-03303-9.

Sellappan Selvaraju

selvarajuars@rediffmail.com; Selvaraju.S@icar.gov.in

1 Reproductive Physiology Laboratory, Animal Physiology, Division, ICAR-National Institute of Animal Nutrition and Physiology, Adugodi, Bengaluru 560030, India

2 Micro Nutrient Laboratory, Animal Nutrition Division, ICAR-National Institute of Animal Nutrition and Physiology, Adugodi, Bengaluru 560030, India

3 LC-MS/MS Platform, Centre for Cellular and Molecular Platforms, NCBS-TIFR, Bengaluru 560065, India

4 ICAR-National Institute of Animal Nutrition and Physiology, Adugodi, Bengaluru 560030, India 


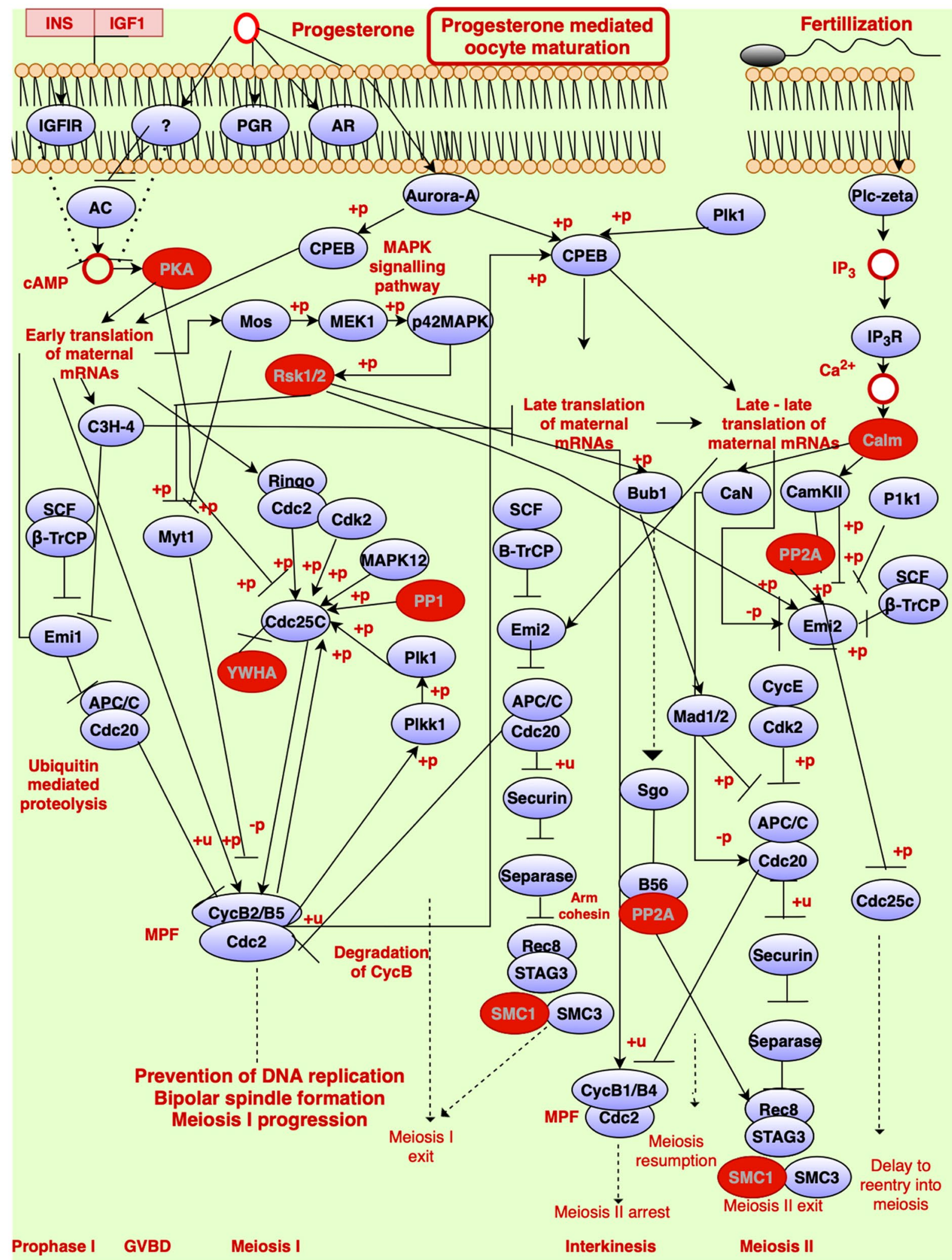

The original article has been corrected.

Publisher's Note Springer Nature remains neutral with regard to jurisdictional claims in published maps and institutional affiliations. 